\title{
BORICUAS CRUZANDO FRONTERAS: AUTOBIOGRAFÍAS Y TESTIMONIOS TRANS PUERTORRIQUEÑOS
}

\author{
Lawrence La Fountain-Stokes \\ University of Michigan, Ann Arbor \\ lawrlafo@umich.edu
}

\section{RESUMEN}

La experiencia trans puertorriqueña se ha plasmado de distintas maneras en los discursos, las entrevistas y las publicaciones de la activista Sylvia Rivera, de la artista Holly Woodlawn, de la estilista y activista Soraya (Bárbara Santiago Solla) y de la artista y profesora universitaria e investigadora Luis Felipe Díaz, también conocida como Lizza Fernanda. La escasez de publicaciones tradicionales en el género de autobiografía trans puertorriqueńa invita a una expansión conceptual, incluyendo teorizaciones sobre el testimonio en Latinoamérica y modalidades alternas de publicación tales como la autopublicación y el uso de la bitácora o blog en Internet. La particularidad de la situación colonial de Puerto Rico y la experiencia de racialización de lxs puertorriqueńxs en Estados Unidos obliga a una cuidadosa lectura atenta a la dimensión racial, étnica, económica y social de las vidas puertorriqueñas trans. Palabras Clave: Puerto Rico, autobiografía, memorias, trans, LGBT.

\section{BORICUAS CROSSING BORDERS: TRANS PUERTO RICAN AUTOBIOGRAPHIES AND TESTIMONIES}

\section{Abstract}

Puerto Rican trans experience has been documented in different ways in the speeches, interviews, and publications of the activist Sylvia Rivera, the artist Holly Woodlawn, the hairstylist and activist Soraya (Bárbara Santiago Solla), and the artist and university professor Luis Felipe Díaz, also known as Lizza Fernanda. The scarcity of traditional publications in the genre of Puerto Rican trans autobiography invites a conceptual expansion, including theorizations on "testimonio" in Latin America and alternate modalities of publication such as self-publishing and the use of online blogs. The particularities of the colonial situation in Puerto Rico and Puerto Ricans' experiences of racialization in the United States requires a careful reading, paying attention to the racial, ethnic, economic, and social dimensions of trans Puerto Rican lives.

KeYwords: Puerto Rico, autobiography, memoirs, trans, LGBT.

DOI: https://doi.org/10.25145/j.clepsydra.2021.21.05

Revista Clepsydra, 21; marzo 2021, pp. 95-120; ISSN: e-2530-8424 


\section{INTRODUCCIÓN}

¿Cómo han plasmado las personas trans puertorriqueñas sus vivencias a través de sus testimonios orales y escritos? La experiencia trans boricua cruza fronteras entre el Caribe, Estados Unidos y otros lugares; se manifiesta en inglés, en español y en espanglish; y aparece de diversas formas y en múltiples géneros literarios. En el caso de la activista pionera puertorriqueña-venezolana Sylvia Rivera, se visibiliza en discursos autorreferenciales, artículos periodísticos y valiosas entrevistas. Esta experiencia trans boricua se transforma en las memorias de Holly Woodlawn, que documentan su participación en la esfera artística alternativa de Nueva York en los años setenta, particularmente en relación con el mundo de Andy Warhol y su «Factory». También se plasma en las memorias, ya sea publicadas como libro o blog, de la dueña de negocio, estilista, candidata política y activista Soraya (Bárbara Santiago Solla) y de la exprofesora universitaria y artista Luis Felipe Díaz/Lizza Fernanda, quien afirma su doble trayectoria (como Luis y como Lizza) usando ambos nombres públicamente ${ }^{1}$. También circula a través de fuentes periodísticas y jurídicas que registran casos de principios del siglo veinte (Laureano 46) y en documentales más recientes sobre San Juan, Nueva York y Chicago como Paris Is Burning (Jennie Livingston, 1990), Las minas de sal (Susana Aikin y Carlos Aparicio, 1990), La transformación (Susana Aikin y Carlos Aparicio, 1995), I Am the Queen (Henrique Cirne-Lima y Josué Pellot, 2010), La aguja (Carmen Oquendo-Villar y José Correa Vigier, 2012), Desmaquilladas (Vivian Bruckman Blondet, 2013), Mala Mala (Antonio Santini y Dan Sickles, 2014) y The Death and Life of Marsha P. Johnson (David France, 2017), en el que aparece la activista Victoria Cruz en sus esfuerzos por esclarecer la muerte (posible asesinato) de su amiga, la pionera activista trans afroamericana Marsha P. Johnson. A su vez, aparece en libros autopublicados como el de Reyna Ortiz, T: Stands for Truth (2017), que versa sobre sus vivencias en Chicago y cómo abandonó la prostitución para dedicarse al trabajo social y de prevención de VIHsida con mujeres trans. Y más recientemente aparece también en la poesía, como en el caso del poeta Raquel Salas Rivera (que usa el pronombre masculino) y de la artista María José, o en los medios sociales y en la prensa, como en los casos de la abogada y activista Victoria Rodríguez Roldán, de la activista Joanna Cifredo, del trabajador social Sebastián Colón-Otero, del chef Paxx Caraballo Moll, del artista de performance transdisciplinario Pó Rodil y del entrenador personal Esteban Landrau, quien ganó fama y gran cobertura mediática tras quedar embarazado de su esposa, la modelo colombiana trans Danna Sultana, con quien tuvo un bebé en $2020^{2}$.

Los testimonios y las memorias, autobiografías y entrevistas trans (o transgénero) puertorriqueñas centran las paradojas y contradicciones de ser sujetos mino-

1 Véase Rodríguez-Madera sobre la experiencia trans femenina en Puerto Rico. En mi libro Translocas ofrezco un análisis de algunas representaciones culturales puertorriqueñas trans. Además, en este mismo dosier, dentro de la sección «Huellas y fragmentos», puede consultarse un texto autobiográfico de Luis/Lizza Fernanda, unx de lxs autorxs analizadxs aquí.

${ }^{2}$ Sobre el nacimiento y registro de Ariel Landrau Pérez, ver Primera hora. 
ritarios en múltiples sentidos, ya sea como entes coloniales (dada la relación política de subordinación entre Puerto Rico y Estados Unidos) -marcados por experiencias frecuentes (pero no exclusivas) de pobreza y exclusión sexual, genérica, racial y lingüística - o como ciudadanxs de segunda categoría, con pasaportes y ciudadanía estadounidense pero sin los derechos plenos que esta ofrece ${ }^{3}$. Señalan el racismo y las exclusiones en Estados Unidos, como en los casos de Sylvia Rivera y Holly Woodlawn. También documentan logros pioneros de sujetos de clase media con educación universitaria, como Soraya, quien realizó su cirugía de afirmación de género en Nueva York en 1975 y obtuvo el cambio de sexo en su acta de nacimiento en 1976, antes de que las leyes puertorriqueñas lo prohibieran (prohibición que duró hasta 2018) ${ }^{4}$, para luego contraer matrimonio (reconocida como mujer heterosexual) en la República Dominicana en 1986, o los gestos pioneros de Luis Felipe Díaz, quien mantuvo su práctica artística como Lizza Fernanda pero también empezó a dictar clases en la Universidad de Puerto Rico manteniendo su nombre masculino; más tarde comenzó a usar ropa femenina y se asumió como mujer. Todos estos textos complementan, retan y expanden la larga tradición de autobiografías sobre la transexualidad y sobre la experiencia transgénero analizada por Jay Prosser, Rafael M. Mérida Jiménez, Jorge Luis Peralta, Juliet Jacques y otres en diversos contextos culturales (Argentina, España, Estados Unidos, Inglaterra), añadiendo la especificidad caribeña y diaspórica.

En este ensayo contextualizaré algunas de estas narrativas autobiográficas en relación con las memorias lésbicas y gais puertorriqueñas para centrarme luego en el análisis de Sylvia Rivera, Holly Woodlawn, Soraya (Bárbara Santiago Solla) y Luis Felipe Díaz/Lizza Fernanda. Propongo una visión expandida de la autobiografía o la memoria tradicional, trazando paralelos con el género del testimonio en su acepción más amplia, es decir, imaginando cómo nosotres mismes como lectorxs o espectadorxs construimos la memoria biográfica a través de los retazos disponibles de la voz del sujeto histórico. A su vez, propongo entender las multiplicidades o el efecto polivalente del prefijo y sustantivo «trans» en referencia al género sexual pero también a la geografía y experiencia diaspórica puertorriqueña transatlántica y transcaribeña, apelando a la visión móvil afrodiaspórica (la travesía, las pedagogías del cruce) que M. Jacqui Alexander propone en su libro Pedagogies of Crossing (2005), tal como resalta la autora trans afrobrasileńa Dora Silva Santana. La transitoriedad y el cambio, la transformación vital, el reto fundamental a las normas sociales y sus convenciones vetustas marcan la experiencia militante trans caribeña y diaspórica y se manifiestan de diversas maneras, inclusive para aquellas personas que no se conciben como activistas. El género literario de la memoria o autobiografía se vuelve

3 Ayala y Bernabe ofrecen un valioso análisis de la situación colonial puertorriqueña en su libro Puerto Rico en el siglo americano. Su historia desde 1898. Ver también Negrón-Muntaner, None of the Above.

4 Véanse Castro-Pérez y Díaz-Morales sobre las luchas relacionadas con el derecho a cambiar el sexo en el certificado de nacimiento en Puerto Rico. 
fundamental en la documentación y reflexión sobre una vivencia frecuentemente marginada, transformadora y potencialmente radical.

\section{CONTEXTO GENERAL LGBT Y ESPECIFICIDAD TRANS}

Hay una importante tradición de memorias queer/cuir o LGBT puertorriqueñas y de textos y materiales autobiográficos (ya sea discursos, cine documental, testimonios, entrevistas y obras narrativas de ficción) en inglés y español, generados mayormente en Estados Unidos y Puerto Rico, sobre la experiencia queer puertorriqueña. Si bien este corpus más amplio no ha sido analizado en conjunto, sí hay valiosos acercamientos a la experiencia activista, literaria y cultural LGBT, queer o cuir puertorriqueña, tanto en la isla (o el archipiélago) y la diáspora, como resaltan dos números especiales de la revista CENTRO Journal de 2007 y 2018 y una serie de valiosos artículos y libros, entre ellos la antología pionera Los otros cuerpos, editada por David Caleb Acevedo, Moisés Agosto Rosario y Luis Negrón'. A su vez, tal vez paradójicamente, podemos afirmar que no hay demasiada conciencia del público o del mundo académico más amplio (no especializado) sobre la existencia de esta tradición de memorias y testimonios queer o trans puertorriqueñxs, ya sea en Puerto Rico, España o Estados Unidos.

En Puerto Rico, muchas veces se ignora este corpus (excepto en muy limitados contextos) debido a la homofobia, lesbofobia y transfobia que históricamente han dominado el campo académico y la sociedad en general. En Estados Unidos, la ignorancia sobre Puerto Rico está ligada al racismo y a la falta de interés en la experiencia minoritaria o colonial, fenómeno que también ha marcado el entorno institucional hegemónico de los estudios queer anglo-americanos, particularmente los que se enfocan en figuras tales como Eve Sedgwick y Judith Butler y que excluyen la experiencia de personas de color (La Fountain-Stokes, «Gay Shame, Latinaand Latino-Style»). En España, Puerto Rico queda frecuentemente opacado por un exagerado interés en Cuba y en otros países latinoamericanos, o reducido a la esfera de la música popular (por ejemplo, al reguetón).

En ese sentido, la «crítica queer de color» (la «queer of color critique») y más recientemente, la «crítica trans de color» han sido fundamentales para señalar y contrarrestar las exclusiones, puntos ciegos y violencias epistémicas de sujetos hegemónicos blancos queer y de otras personas que sistemáticamente excluyen a los sujetos racializados, ya sea como objeto de análisis o como creadores de teoría, como seña-

5 Sobre los estudios queer puertorriqueños, véase Aponte Parés et al., al igual que La Fountain-Stokes y Martínez-San Miguel. Guzmán ofrece un análisis sociológico de las negociaciones identitarias de hombres gais puertorriqueńos en Nueva York. En su libro Boricua Pop, Negrón-Muntaner analiza diversas representaciones culturales puertorriqueñas desde la perspectiva de la sexualidad queer, incluyendo la producción cultural de Holly Woodlawn. En San Juan Gay, Laureano documenta más de cincuenta años de historia LGBT. 
lan José Esteban Muñoz en Disidentifications: Queers of Color and the Performance of Politics (1999) y Michael Hames-García en su acertada evaluación de la teoría queer hegemónica ("Queer Theory Revisited») publicada en 2011. Esta problemática se reproduce en España, como se documenta en las cruciales antologías Resentir lo queer en América Latina: diálogos desdelcon el Sur, editada por Diego Falconí Trávez, Santiago Castellanos y María Amelia Viteri en 2014, y en Inflexión marica: escrituras del descalabro gay en América Latina, editada por Falconí Trávez en 2018, ambas publicadas por la Editorial Egales.

Se trata, en consecuencia, de descolonizar tanto la mirada crítica y el soporte teórico como de valorizar narrativas o relatos minoritarios, a la vez que se privilegia una apertura hacia la teoría trans latinoamericana y caribeña. El creciente reconocimiento de Sylvia Rivera como teórica latina o de color ha sido un paso fundamental, pues permite reorientar ciertas narrativas de la liberación gay que excluían a las personas trans y que no reconocían a lxs activistas no universitarixs como teóricxs. Igual de importantes son las contribuciones de Marlene Wayar en Travesti. Una teoría lo suficientemente buena (2018), libro que reúne múltiples voces a través de conversaciones con la poeta chilena Claudia Rodríguez y con la artista "trans sudaca» Susy Shock, entre otres, quienes enfatizan la violencia familiar contra les niñes trans y resaltan la metodología de la entrevista o conversación como método de generar conocimiento. También resultan útiles las afirmaciones de la artista afrodominicana transdisciplinar Johan Mijail en su ensayo «traves'Tismo cultUral: tecnodEcolonialidad, promiscuidad escRitural dominicanCUIR», donde afirma: «EN ESTA INCERTIDUMBRE IDENTITARIA LO ÚNICO QUE SÉ ES QUE HOMBRE NUNCA HE SIDO. Mi cuerpo es trans, mi cuerpo no tiene patria» (59); pone así de relieve migración, diáspora y afrodescendencia como ejes centrales para un proyecto de descolonización trans/travesti caribeño, antirracista y contrasexual.

El incipiente campo académico de los estudios trans en Estados Unidos también ha negociado estas tensiones, luchando por señalar y entender cómo la raza y el racismo impactan las vidas trans, según advierten C. Riley Snorton en Black on Both Sides: A Racial History of Trans Identity (2017) y numerosxs colaboradorxs de la antología The Transgender Studies Reader 2 (2013), coeditada por Susan Stryker y Aren Z. Aizura, entre ellxs, Jessi Gan, Marcia Ochoa y Vek Lewis. Esta especificidad geográfica que presta atención a la raza y a la etnicidad y cuestiona la supremacía blanca y los legados coloniales también se percibe en los artículos que forman parte del número especial de la revista TSQ: Transgender Studies Quarterly dedicado a «Trans Studies en las Américas», coeditado por Claudia Sofía Garriga-López, Denilson Lopes, Cole Rizki y Juana María Rodríguez en 2019. Se da de igual manera en el trabajo de Francisco J. Galarte, por ejemplo, en su libro Brown Trans Figurations: Rethinking Race, Gender, and Sexuality in Chicanx/Latinx Studies (2021), que se centra en la violencia contra personas trans latinas, es decir, en los transhomicidios y transfeminicidios. Las contribuciones de Snorton, de lxs autorxs en estas antologías y revistas y de Galarte centran un modelo teórico interseccional "que subraya que el género, la etnia, la clase, u orientación sexual, como otras categorías sociales, lejos de ser "naturales" o "biológicas" son construidas y están interrelacionadas” (Platero Méndez 56). 
Podemos localizar las memorias trans puertorriqueñas que analizo en este artículo en relación con otros valiosos textos boricuas que exploran el tema de la diversidad sexual, en los que también percibimos cruces geográficos, lingüísticos y vivenciales. Entre las memorias gais y lésbicas puertorriqueñas más importantes se encuentran las de Antonio Martorell, Luisita López Torregrosa, Antonia Pantoja, Joseph F. Delgado, David Caleb Acevedo y Xavier Valcárcel; aquí notamos la variación en el lenguaje (ya sea el inglés o el español, aunque en algunos casos se han traducido y se encuentran disponibles en ambos idiomas), el lugar desde el que se escribe (Puerto Rico o Estados Unidos) y el tipo de publicación (en casas editoriales transnacionales, como en el caso de López Torregrosa, en pequeñas editoriales o a través de la autopublicación). Estas memorias varían mucho en relación con el grado de exposición del tema de la diversidad sexual. Algunas apenas sugieren experiencias queer, por ejemplo, el caso del pintor y artista gráfico Antonio Martorell, quien habla de manera discreta sobre su crianza y sus transgresiones de género en el barrio sanjuanero de Santurce, centro de la modernidad isleńa de los ańos cuarenta y cincuenta, donde también residía su tía lesbiana, quien aparece caracterizada como seductora en serie de numerosas mujeres ${ }^{6}$. Otras lo emplazan como eje fundamental, como es el caso de Joseph F. Delgado en el libro Ser diferente en Puerto Rico. El peso de la memoria, de 2017, tal como apuntan Efraín Barradas («Etnografía del hostigamiento») y Wilkins Román Samot (Ser diferente en Puerto Rico). Más aún, el Diario de una puta humilde, de David Caleb Acevedo, precisamente se nutre de la hipervisibilidad, pues, como señala Rubén Ríos Ávila, Diario... «es una versión o mutación triple equis de aquellos relatos de encuentros sexuales furtivos del escritor chicano gay John Rechy, alrededor de los setenta del siglo pasado, autor de textos como City of Night y Numbers", en los que el recuento de sexo con clientes y amigos y otras aventuras picarescas estructuran el texto. En su artículo «Queering Puerto Rican Women's Narratives: Gaps and Silences in the Memoirs of Antonia Pantoja and Luisita López Torregrosa», Lourdes Torres resalta las particularidades de las memorias escritas en inglés por mujeres puertorriqueñas lesbianas que nacieron en el Caribe y que emigraron a Estados Unidos como adultas. Un notable blog centrado en la narración autobiográfica es Memorias de un Gay Sesentón (ahora llamado Memorias de un Setentón), de Gerardo Torres Rivera, autor a su vez de la novela Radiotransistor.

Escritorxs como Manuel Ramos Otero, Magali García Ramis y Ángel Lozada han logrado importantísimas obras a través de la autoficción y de la autobiografía como proyección crítica, un concepto que discuto en mi libro Queer Ricans: Cultures and Sexualities in the Diaspora, donde analizo un ensayo crítico de Ramos Otero sobre el poeta español Luis Cernuda de 1988 que sirve como espejo de su propia vida (Ramos Otero 105-119). En dicho ensayo («La ética de la marginación en la poesía de Luis Cernuda»), las vidas de Ramos Otero y Cernuda se confunden en

\footnotetext{
${ }^{6}$ Sobre Martorell, véase La Fountain-Stokes, «Memorias sensuales. La piel de la escritura de Antonio Martorell», en Escenas transcaribeñas, 42-51.
} 
paralelos vitales, y la crítica literaria parece más un juego de autoproyección visible para las personas que conocen la biografía de ambos. Ramos Otero, considerado el escritor puertorriqueño abiertamente gay más importante del siglo veinte (es decir, que tematizó abiertamente la homosexualidad en su obra como eje central y estructurante y que tomó posturas públicas al respecto, tanto en Puerto Rico como en Nueva York), veía toda su obra de ficción (y tal vez hasta su poesía) como autobiográfica, como explicitó en su ensayo póstumo de 1990, «Ficción e historia. Texto y pretexto de la autobiografía» (Ramos Otero 120-125).

También se da el caso de quienes, como la activista trans Sylvia Rivera, ofrecen una narrativa autobiográfica a través de sus discursos públicos y entrevistas, asemejándose más al modelo teórico del testimonio latinoamericano. Este reconoce las serias limitaciones o dificultades enfrentadas por sujetos minoritarios subalternos o marginados, frecuentemente sin acceso a la educación formal, y que deben valerse del discurso público y a veces de la colaboración con un sujeto letrado. El caso ejemplar en el contexto puertorriqueño es el texto de Juanito Xtravaganza (Juan Rivera), recopilado, publicado y analizado por Arnaldo Cruz-Malavé en su valioso libro Queer Latino Testimonio, Keith Haring, and Juanito Xtravaganza: Hard Tails de 2007. Aquí conviene recalcar las limitaciones de algunos sujetos que no llegaron a escribir una memoria o autobiografía tradicional, para expandir la definición (o el alcance) de la categoría, reconociendo, como Sylvia Molloy en Acto de presencia. La escritura autobiográfica en Hispanoamérica (1996), que algunos sujetos minoritarios (mujeres, negrxs, emigradxs, homosexuales) sí tuvieron acceso a la palabra escrita, como también señala Robert Richmond Ellis en sus investigaciones sobre la autobiografía gay hispánica. En otros casos, como el de la artista trans puertorriqueña Barbra Herr (Bárbara Hernández), la falta de una autobiografía se compensa a través del monólogo teatral (como en su obra Trans-Misión, de 2017, en la que articula su misión «trans»), complementada por las entrevistas que aparecen en el documental Portrait of a Lady: Story of Barbra Herr (2012), de Julio Gómez, y por su activa participación en Facebook, donde Herr introduce con frecuencia comentarios sobre su vida.

\section{EL CASO DE SYLVIA RIVERA}

Reconocida a nivel internacional por su participación en la revuelta de Stonewall en 1969 y por su trabajo comunitario posterior, la activista Sylvia Rivera apenas llegó a publicar en vida, situación que se entiende plenamente si consideramos que abandonó su hogar y la educación formal a los diez años de edad, cuando escapó de su contexto familiar represivo para vivir en la calle y trabajar en la prostitución junto a otras puertorriqueñas en la zona de Times Square de Nueva York y que siguió viviendo en la calle de manera crónica a través de su vida. De padre puertorriqueño y madre venezolana, Rivera nació en 1951 y fue criada por su abuela materna en el Bronx tras el suicidio de su madre y el abandono de su padre. Sylvia apenas tenía tres años cuando su madre ingirió veneno para ratas y trató de que Sylvia se suicidara con ella. «Viejita», la abuela que pasó a criar a Rivera, sentía emo- 
ciones encontradas hacia su niete huérfane y comenzó a maltratarle cuando le niñe mostró comportamiento afeminado (Gan 129), lo cual llevó a que Rivera abandonara su hogar en 1962, poco antes de cumplir once años.

Si bien Rivera nunca publicó memorias o una autobiografía, su historia de vida aparece en numerosas entrevistas y transcripciones de sus charlas publicadas antes y después de su muerte en 2002. Estas narrativas orales captan sus experiencias vitales de manera detallada y las transforman en la historia colectiva de un sujeto histórico que se posiciona en relación con sus colaboradorxs, por ejemplo, a Marsha P. Johnson. Fue con Johnson con quien Rivera empezó Street Transvestite Action Revolutionaries, un grupo militante radical conocido como STAR («estrella») que se dedicaba (desde la marginalidad y la pobreza) a albergar a niñes y jóvenes trans sin hogar y a colaborar con grupos tales como el Partido de las Panteras Negras (el Black Panther Party) o los Young Lords (Gan 133). La historia de Rivera se encuentra enmarcada por momentos de profunda transformación social, ya sean los motines del verano de 1969 o los conflictos dentro del movimiento gay y lésbico estadounidense que cristalizaron en el rechazo y la falta de solidaridad y de compromiso radical con las mujeres trans encarceladas, víctimas de abuso sexual. Esto se visibilizó en la reacción hostil que Rivera recibió al tratar de hablar sobre estos temas en Nueva York durante la celebración del Christopher Street Liberation Day de 1973 (Muñoz, The Sense of Brown 131-133).

En este importante discurso de 1973, Rivera se posiciona como persona que ha experimentado en carne propia la violencia del Estado, pero que también ha sentido el rechazo y la falta de solidaridad de su propia comunidad. En sus propias palabras: «I have been beaten. I have had my nose broken. I have been thrown in jail. I have lost my job. I have lost my apartment for gay liberation, and you all treat me this way? What the fuck's wrong with you all? Think about that!» $[\mathrm{Me}$ han golpeado. Me han roto la nariz. Me han echado en la cárcel. He perdido mi trabajo. Perdí mi apartamento por la liberación gay, ¿y así es que me tratan? ¿Qué coño les pasa a ustedes? ¡Piensen sobre eso!] (LoveTapesCollective). Luego pasa a hablar de sus compañeras encarceladas y a exigir solidaridad y apoyo, y denuncia al público por pertenecer a una clase media blanca acomodada y conservadora («men and women that belong to a white middle class white club. And that's what you all belong to!» [hombres y mujeres que pertenecen a un club blanco de clase media blanca. ¡Y eso es a lo que ustedes pertenecen!]) (LoveTapesCollective). En este caso, la circulación de un video grabado en esa ocasión (ahora compartido por el colectivo lésbico LoveTapesCollective ${ }^{7}$ que pasó a aparecer en películas documentales y más recientemente a través de YouTube y Vimeo, al igual que la transcripción y traducción de su discurso, logra captar el contenido de su mensaje y también la profunda emoción que lo acompaña. Sirve como denuncia de la transfobia que por muchos años marcó el movimiento gay y lésbico en Estados Unidos.

\footnotetext{
7 Tedjasukmana comenta sobre la historia de este video y su impacto y circulación.
} 
En un breve ensayo sobre la importancia del género del testimonio, Arnaldo Cruz-Malavé declara: "testimonio is the resulting textual or visual product of an individual act of witnessing and/or experiencing an abject social state that is more than individual, that is indeed collective» [el testimonio es el producto textual o visual que resulta de un acto individual de testimoniar y/o experimentar un estado social abyecto que es más que individual, que es efectivamente colectivo] (Testimonio 228). Cruz-Malavé enfatiza la manera en que el testimonio centra y valida «the figure of the speaker who narrates his or her story under the duress of the social order's threat of abjection, invisibility, or death» [la figura de la hablante que narra su vida bajo la coacción de la amenaza de abyección, invisibilidad o muerte impuesta por el orden social] (228). Vemos estos retos de abyección, invisibilidad o muerte a manos del orden social en las narraciones de Rivera, ya sea en las entrevistas efectuadas por el historiador Martin Duberman que aparecen en su libro Stonewall (1993) o en entrevistas; por ejemplo, la concedida al periodista y activista trans Leslie Feinberg (1998). También se pueden apreciar en discursos como el que Rivera pronunció en 2001 en una reunión del grupo Latino Gay Men of New York -luego incluido en la revista CENTRO Journal en 2007- en el que habla sobre el activismo que marcó su vida a finales de los noventa y principios de los 2000 , por ejemplo, en relación con el asesinato no resuelto de la mujer afroamericana trans Amanda Milan ${ }^{8}$. Sobre la base de estos materiales, la investigadora trans Jessi Gan pudo enlazar un relato de vida que se asemeja al gesto autobiográfico del testimonio, es decir, que logra usar las palabras del sujeto excluido (en este caso, de Rivera) para ofrecer una visión cohesiva de su vida (Gan 129-134).

En un artículo reciente (La Fountain-Stokes, «Life and Times»), analizo cómo Rivera pasó de ser un sujeto repetidas veces ignorado a obtener enorme visibilidad. Mi gesto crítico se asemeja al del investigador Tim Retzloff (2007), quien compara el legado de Rivera y su proceso de memorialización con la experiencia del colombiano-americano José Sarria en San Francisco, California. El pensamiento de Rivera ahora circula en inglés y en español en la antología Street Transvestite Action Revolutionaries gracias al trabajo editorial del colectivo anarquista Untorelli Press, que recopiló varias de estas entrevistas y charlas, incluyendo la que grabé en 2001 en la reunión de Latino Gay Men of New York. La principal limitación del libro (y de su traducción al castellano por la Distribuidora Peligrosidad Social de Madrid en 2014) es que no incluye las fuentes bibliográficas ni reconoce el trabajo periodístico o académico de las personas que se dedicaron a recopilar, editar y publicar estos textos (no incluye nuestros nombres), invisibilizando así la labor de personas de color queer, de personas trans, de periodistas, de profesores y de estudiantes. En sus gestos libertarios, Untorelli Press y la Distribuidora Peligrosidad Social popularizan y promueven el pensamiento radical de Sylvia Rivera y de Marsha P. Johnson,

${ }^{8}$ En 2001, invité a Sylvia Rivera, grabé su charla, la transcribí y la edité con la asistencia de una estudiante de pregrado. La charla se publicó en 2007 en CENTRO Journal junto con los artículos de dos estudiantes de posgrado. Ver Gan; Retzloff; Rivera, Sylvia Rivera. 
pero a su vez cometen otro tipo de violencia: la de no reconocer el proceso colectivo de documentación que llevó a la validación, institucionalización o canonización del pensamiento de Rivera como figura clave del movimiento trans.

\section{HOLLY WOODLAWN}

Famosa por su participación en las películas Trash (1970) y Women in Revolt (1971), ambas dirigidas por Paul Morrissey y producidas por Andy Warhol, y reconocida como una "Superstar» (Superestrella) de Warhol, la cantante de cabaret y artista trans puertorriqueña y judía Holly Woodlawn publicó sus memorias, $A$ Low Life in High Heels: The Holly Woodlawn Story, en 1991 con el sello HarperPerennial, parte de la multinacional HarperCollins Publishers. Woodlawn escribió el libro en colaboración con Jeff Copeland, quien aparece como coautor, y el libro incluye una sección de fotos en blanco y negro. Su portada lleva una glamorosa imagen de estudio, también en blanco y negro, en la que apreciamos el rostro y el hombro desnudo de Woodlawn, quien aparece bellamente maquillada y peinada, con un precioso pendiente de brillantes que cae de su oreja hacia su hombro. La foto se asemeja a las tomadas a estrellas de Hollywood de los años cuarenta del siglo pasado.

El libro de Woodlawn cuenta con una introducción por Paul Morrissey, un subsubtítulo ("A Walk on the Wild Side with Andy Warhol's Last Superstar») que enfatiza su vínculo con Warhol y con el cantante de rock Lou Reed (autor de la canción Walk on the Wild Side, que popularizó la historia de vida de Holly) y cuatro citas en la contraportada, incluyendo dos de los íconos queer Harvey Fierstein y Quentin Crisp, quienes afirman el vínculo de Woodlawn con la escena neoyorquina de vanguardia, que incluía transformistas y mujeres trans tales como Candy Darling y Jackie Curtis. Como ha señalado Frances Negrón-Muntaner en Boricua Pop, todos los materiales publicitarios minimizan la especificidad puertorriqueña de la artista; la misma Woodlawn oscila en sus memorias entre la representación idealizada de Puerto Rico como un paraíso tropical y la categorización sensacionalista de las travestis puertorriqueñas de Nueva York como salvajes peligrosas («psycho queens») de las que se tiene que proteger (Woodlawn y Copeland 112-113).

De madre puertorriqueña y padre alemán-americano, Woodlawn nació en Puerto Rico en 1946, pero creció en Miami con su madre y su padrastro judío polaco-americano, quien la adoptó. A diferencia de Sylvia Rivera, Woodlawn tuvo una infancia estable, marcada por un hogar más tradicional, pero su situación empeoró durante la adolescencia. En A Low Life in High Heels (que podríamos traducir como Una vida baja en tacones altos), Woodlawn describe el dramático descenso social y empobrecimiento que experimentó como resultado de fugarse de su casa a principios de los años sesenta, cuando tenía quince años. También menciona sus limitadas oportunidades de empleo en la ciudad de Nueva York como joven adolescente trans que no tenía un diploma de escuela superior. Al principio (al igual que Rivera), trabajó en la prostitución en Times Square. Más tarde, los únicos trabajos que podía conseguir eran de oficinista, de modelo en tiendas o de ventas, los cuales podía mantener con tal de que pasara por -o fuera percibida-como mujer, en una época 
en que travestirse era ilegal, punible con encarcelamiento y socialmente rechazado. Este rechazo se repitió cuando la expulsaron de la escuela de cosmetología por presentarse en clase con maquillaje y vestimenta femenina.

A Low Life in High Heels es un recuento picaresco lleno de aventuras graciosas, escrito con el humor y la chispa que siempre caracterizaron a la artista, pero también lleno de anécdotas serias sobre los retos que enfrentó, por ejemplo, sus experiencias viviendo en la calle, o sin dinero, o en la cárcel, donde acabó tras falsificar la firma de una diplomática para retirar fondos de una cuenta bancaria. En sus páginas, leemos sobre noches de alta sociedad que se alternan con otras marcadas por una enorme pobreza. También encontramos episodios en que Woodlawn decidió tratar de vivir como hombre gay (con apariencia masculina) para complacer a sus padres y leemos sobre la ansiedad que esto le provocaba y los deseos que llegó a sentir de someterse a una cirugía de afirmación del género.

$\mathrm{Al}$ igual que los retos del género sexual y de la vida trans, el tema de la pobreza resulta absolutamente central en el libro, algo que ata el relato de Woodlawn a las vivencias radicalmente distintas de Sylvia Rivera. También comparten su localización en Nueva York y la preponderancia del idioma inglés en sus vidas. La mayor diferencia entre las dos radica en que Woodlawn nunca se consideró activista y no militó por luchas sociales, mientras que sí tuvo extensos contactos con el mundo de la clase alta, particularmente a través de Andy Warhol y su círculo artístico. Es aquí donde se percibe una tensión radical, dada la situación de precariedad en la que Woodlawn se encontró con gran frecuencia y el racismo de un mundo dominado por hombres blancos gais que reproducían y magnificaban los prejuicios y las exclusiones dominantes en Estados Unidos. Así, las páginas de A Low Life in High Heels cobran carácter de denuncia, tanto de la explotación económica que sufrió la autora (por ejemplo, el hecho de que sólo le pagaran $\$ 125$ por su trabajo en la filmación de Trash, cuando la película generó $\$ 4000000$ de dólares americanos en ganancias), como del sistema de mecenazgo que Warhol desarrollaba con sus artistas (un tipo de asistencia social o beneficencia parasítica), que mantenía a quienes colaboraban en sus proyectos en estado de deuda y dependencia. Como señala Woodlawn,

Every now and then, usually after too many drinks, I would feel like an exploited fool. But then, all the Superstars were Andy's fools. We acted like lunatics on film and he made millions off of it. Sometimes I felt cheated and sometimes I didn't, but when I did, I would become totally unraveled and incensed with anger. So, to release my frustrations, I'd march over to the Factory, snort flames, stomp my feet, and carry on like a mad banshee. "That goddamn son of a bitch is making millions off of me and I'm living in poverty!» I screamed (163).

[Cada cierto tiempo, generalmente después de tomar demasiadas copas, me empezaba a sentir como una tonta explotada. Pero es que todas las Superestrellas éramos las tontas de Warhol. Nos comportábamos como lunáticas en sus películas y él ganaba millones de dólares. A veces me sentía engañada y otras veces no, pero cuando me pasaba, me desequilibraba por completo y me llenaba de rabia. Así que, para liberar mis frustraciones, marchaba hacia la Factory, resoplaba llamas, pisoteaba y me comportaba como una banshee rabiosa. «iEse maldito hijo de puta está ganando millones gracias a mí y yo viviendo en la pobreza!» gritaba]. 
Esta experiencia de sentirse como «an exploited fool» (una tonta explotada) la convierte en un tipo de "transloca», para usar el término que he empleado en mi análisis de travestis, transformistas y mujeres trans puertorriqueñas (La Fountain-Stokes, Translocas); una figura rabiosa que se vuelve «a mad banshee» (una banshee encolerizada) en su frustración y rechazo.

El otro aspecto central de la narrativa tiene que ver con su afirmación como persona de color, o al menos como alguien que se oponía al discurso racista. Esto se observa en sus comentarios sobre la filmación de Trash, cuyo guion estaba basado en la improvisación. En la película, Woodlawn interpreta el papel de Holly Santiago, una mujer (cisgénero) que busca defraudar al Gobierno para recibir asistencia social. Cuando el trabajador social hace comentarios racistas en contra de los negros, Woodlawn indica que la filmación se volvió el escenario de encarnecidas peleas, marcado por la rabia que ella sintió como reacción somática o visceral:

Michael was my first experience with a professional, unionized actor [...] When we weren't filming, we would be yukking it up in the back, but when we did the scene, he suddenly became this pain-in-the-ass welfare worker who didn't like me at all. I was so intimidated and at a loss for words, until Michael made a crack about the Negroes cranking out babies every nine months to get on welfare. Well, honey, I was livid! Beverly Johnson was the top model of the year and he's talking about negroes cranking out babies to get on welfare? The NAACP was going to picket this movie for sure! I became so upset by this racial slur that I actually began to take him personally. I was no longer Holly Woodlawn playing Holly Santiago in a movie. I had made the transition, and this was real. Needless to say, we got into a big uproarious fight, with everybody yelling, screaming, and carrying on. The scene had to be shot five times! (145).

[Michael fue mi primera experiencia con un actor profesional sindicalizado. [...] Cuando no estábamos filmando, nos pasábamos parloteando en la parte de atrás, pero cuando hicimos la escena, él de repente se volvió un trabajador social insufrible que no me soportaba. Yo estaba tan intimidada y sin palabras, hasta que Michael comentó que los negros tenían bebés cada nueve meses para recibir asistencia social. Querida, ¡me enfurecí de inmediato! Beverly Johnson era la modelo del año ¿y él está hablando de personas negras que están pariendo para recibir asistencia social? ¡La NAACP iba a protestar en contra de esta película de seguro! Me ofendí tanto por este insulto racial que lo empecé a tomar personalmente. Ya no era Holly Woodlawn interpretando el papel de Holly Santiago en una película. Había transicionado, esto era real. No hace falta decirlo, nos metimos en una pelea enorme y todo el mundo se puso a gritar a toda boca. ¡Tuvieron que rodar la escena cinco veces!].

En este relato, Woodlawn sugiere que su política de la comedia iba acompañada de un compromiso social y de una solidaridad racial que cuestionaba y retaba los presupuestos racistas de su época. 


\section{SER (O TRANSFORMARSE EN) SORAYA}

Si bien A Low Life in High Heels: The Holly Woodlawn Story resalta una variedad de temas sociales, Woodlawn sugiere que su propósito principal consiste en entretener y documentar la escena artística, más que hacer una intervención política. Hecha a mano. Disforia de género, de Soraya (Bárbara Santiago Solla), se posiciona de manera diferente, pues en este volumen sí se aprecia un compromiso social más evidente, vinculado a luchas sociales y al activismo en Puerto Rico. La autora enfatiza su rol pionero, sus luchas en las cortes, su candidatura electoral (no exitosa) a legisladora municipal de Carolina como representante del Partido Nuevo Progresista y la visión política y social que transmitió a través del activismo y de sus frecuentes interacciones con los medios noticiosos, por ejemplo, como representante de «Puerto Rico para Tod@s», organización liderada por el activista gay Pedro Julio Serrano, una de las figuras mediáticas principales del archipiélago (Laureano 225)9.

El libro de Soraya, pionero en su género en Puerto Rico, fue autopublicado por la autora en 2014 con la asistencia profesional de la poeta y editora Mairym Cruz Bernal, dueña de Lúdika Proyectos, una editorial independiente de autoedición cuidada que colabora con autorxs ${ }^{10}$. Según relata Cruz Bernal, Soraya entregó un manuscrito que luego se mecanografió, editó en conversación con la autora, diagramó y publicó en Colombia, con una tirada de aproximadamente 500 ejemplares sufragada por la autora.

Hecha a mano cuenta con una llamativa portada y contraportada que la autora escogió (dos fotos de Soraya: una como joven rubia de pelo largo vestida en una especie de bikini, sentada en un cojín cerca del suelo, con las piernas dobladas, una bajo la otra, mirando hacia abajo; la otra, una primera toma de su rostro, mirando directo a la cámara, un poco mayor de edad). El libro posee un atractivo diseño gráfico a cargo del artista Néstor Barreto que integra múltiples materiales visuales de gran valor, incluyendo fotos, documentos legales y recortes de artículos de prens $\mathrm{a}^{11}$. También tiene la particularidad de que, a diferencia de lo que suele ser habitual, no hay sangría en el primer renglón de cada párrafo, sino en el resto de los renglones, una decisión de estilo que invierte la norma común y refleja a nivel visual la transgresión vital de la autora. Soraya frecuentemente vendía su libro en eventos públicos, como los conversatorios sobre el documental Mala Mala (2014), dirigido por Antonio Santini y Dan Sickles, en el que apareció como figura central. Al ser un libro autopublicado, su circulación fue limitada y nunca contó con una distribución amplia.

Diversas autoras trans pioneras, como la estadounidense Kate Bornstein (quien publicó $A$ Queer and Pleasant Danger: A Memoir en 2012), han enfatizado

${ }_{9}$ Carolina es un municipio aledaño al municipio de San Juan y forma parte de la zona metropolitana de la ciudad capital. Cada municipio de Puerto Rico tiene su propia legislatura (Álvarez Rivera).

${ }^{10}$ Entrevista telefónica, Mairym Cruz Bernal, 5 de noviembre de 2020.

${ }^{11}$ Cruz Bernal y Barreto no son identificados por nombre en el libro. 
la centralidad e importancia de las memorias trans como gesto vital, comunitario y político y también la manera en que contar su historia puede ser transformador y constituir un reto para una sociedad que anticipa y exige ciertos relatos de integración y asimilación (Schewe 671). Como afirma Sarah Ray Rondot, «autobiography can be a community-building tactic and political tool of personal and collective survival for trans* authors who publish» [las autobiografías pueden ser una táctica de creación comunitaria y una herramienta política para la sobrevivencia personal y colectiva para lxs autorxs trans que publican] (528). Estas memorias y estos relatos autobiográficos tienen una función social de documentación y afirmación: indican la existencia de sujetos marginalizados y olvidados, a la vez que afirman la particularidad de una vida específica. En Reading Autobiography: A Guide for Interpreting Life Narratives, Sidonie Smith y Julia Watson han señalado la importante función de estos relatos, particularmente para las mujeres. Anteriormente hice referencia al trabajo de Sylvia Molloy, Robert Richmond Ellis, Rafael M. Mérida Jiménez y Jorge Luis Peralta, quienes se enfocan en la especificidad hispánica del género, particularmente para sujetos minoritarios. Hecha a mano. Disforia de género se une a estos esfuerzos, siendo la primera (y, hasta la fecha, única) autobiografía o libro de memorias trans publicado en Puerto Rico.

Bárbara Santiago Solla, mejor conocida como Soraya, nació en 1947 en San Juan de madre y padre puertorriqueños. Tuvo una infancia marcada por conflictos y por el abuso físico que su comportamiento generaba tanto en el hogar como en la escuela, como relata en sus memorias. Algunos de estos conflictos tenían que ver con que «orinaba ñangotada y no de pie como lo hacen los varones» (10), jugaba con muñecas, a las cuales vestía con retazos de tela, y a los seis años declaró que tenía "un noviecito" en la escuela, de quien andaba cogida de manos, lo cual causó gran consternación (19). Soraya denuncia repetidas veces haber sido considerada un niño homosexual ("Cuánta gente ponía su cuello en un picador para aseverar que yo era homosexual. Nada más lejos de la verdad», 13), cuando ella entiende que padecía de disforia de género. Las acusaciones sobre su supuesta homosexualidad se hacían empleando el léxico popular, al indicar, por ejemplo, que «el hijo de Alicia o Monchile (apodo de mi papá), es pato; su hijo le salió maricón» (17, cursiva en el original). De hecho, Soraya centra su libro en explicar y promover más conocimiento sobre la disforia de género como diagnóstico médico, valiéndose de la definición del DSM-5 (la quinta edición del Manual diagnóstico y estadístico de los trastornos mentales publicado por la Asociación Estadounidense de Psiquiatría), que la define como «una marcada incongruencia entre el género experimentado/expresado y el género asignado durante al menos seis meses» (Soraya 3). La autora también explica la marginación que sentía, que llevaba a sentimientos de locura y suicidio: «hasta me hicieron sentir como un fenómeno de circo" (16).

El libro incluye no sólo fotos de la autora, sino también imágenes facsímiles de numerosos artículos de prensa y de reportes legales relacionados con su persona, entre ellos la petición de corrección de nombre y sexo sometida al Tribunal de Distrito de Puerto Rico, Sala de Carolina (1975); el certificado de nacimiento con los cambios indicados; un Extracto de Acta dando fe del matrimonio de Bárbara Santiago Solla en la República Dominicana en 1986; y una carta de 1987 de Guillermo 
Mojica Maldonado (el secretario interino de Justicia del Estado Libre Asociado de Puerto Rico) dirigida al Sr. James H. Walker (director de distrito del Servicio de Inmigración y Naturalización), en el que se pronuncia a favor del reconocimiento del matrimonio de Soraya en la República Dominicana, escrita en relación con la solicitud de asesoramiento de Walker,

en torno a si es válido en Puerto Rico el matrimonio entre un hombre y una mujer, cuando esta segunda parte obtuvo la clasificación sexual por medio de una intervención quirúrgica de cambio de sexo y mediante un trámite judicial dentro del cual se ordenó al Registro Demográfico de Puerto Rico enmendar la inscripción de nacimiento para reflejar el nuevo nombre y el cambio de sexo de masculino a femenino (66).

El secretario Mojica Maldonado afirmó que «en el caso bajo estudio podría estimarse válidamente que concurre la principal característica definitoria del matrimonio según el Código Civil de Puerto Rico, vale decir, un contrato civil entre un hombre y una mujer» (71) y en base a esta recomendación, el esposo de Soraya (un ciudadano dominicano) logró autorización para entrar, trabajar y vivir en Puerto Rico. Consta por estos y otros ejemplos que el libro Hecha a mano es un archivo de documentación histórica que complementa el relato de Soraya con fuentes primarias y secundarias que permitirían un análisis más detallado ${ }^{12}$.

Por otra parte, la participación protagónica de Soraya en el documental Mala Mala y en muchas presentaciones y conversatorios sobre el mismo implicaron gran visibilidad y contacto con numerosas personas. Hay mucho de autoafirmación, por no decir de bien merecido alarde físico, por ejemplo, en la provocadora imagen de la portada de Hecha a mano, la cual sugiere que al menos uno de los motivos de la publicación del libro fue celebrar (o recordar) su belleza física de juventud, que contrasta con el porte de señora recatada de la autora en 2014, particularmente su representación en el documental Mala Mala, en el que se presenta como respetable dueña de una peluquería que tiene diferencias ideológicas con mujeres trans más jóvenes (por ejemplo, con Ivana Fred), pues estas lucen sus cuerpos femeninos de manera hipersexualizada, como he señalado en un artículo (La Fountain-Stokes, «Mala Mala»). (De hecho, es importante recalcar que Soraya no se identificaba como mujer trans, sino como mujer heterosexual que sufría de disforia de género).

Hacia el final de su vida, Soraya estaba muy integrada en asociaciones para personas de la tercera edad en Puerto Rico, particularmente con el grupo Waves Ahead de abogacía y servicios para adultos mayores LGBT, liderado por Wilfred Labiosa, un nuevo sector antes no reconocido en el archipiélago (Agencia EFE). La cobertura periodística de la muerte de Soraya en 2020 adquirió carácter internacio-

12 El libro también incluye el facsímil de la partida de divorcio de 1991 emitida por el Servicio Judicial de la República Dominicana y la Certificación de Candidatos a Elecciones Generales otorgada por la Comisión Estatal de Elecciones del Estado Libre Asociado de Puerto Rico en 2007, certificando que Bárbara Santiago Solla era candidata al cargo de legisladora municipal de Carolina. 
nal y fue reseñada en Estados Unidos en el New York Times (Robles), al igual que en Puerto Rico (Delgado Rivera). El fallecimiento de la autora también ha impactado sobre la circulación del libro y su hermana Carmen Santiago Solla se encuentra realizando gestiones para publicar un segundo manuscrito inédito ${ }^{13}$.

\section{LIZZA FERNANDA / LUIS FELIPE DÍAZ: ENTRE LA UNIVERSIDAD Y EL ESCENARIO}

Sylvia Rivera, Holly Woodlawn y Soraya (Bárbara Santiago Solla) enfatizan sus experiencias de vida y su contexto social e histórico valiéndose de entrevistas y charlas o discursos (Rivera), de un libro publicado por una editorial multinacional (Woodlawn) o autopublicando y sufragando los gastos de edición, diagramación e impresión (Soraya). El relato autobiográfico de Lizza Fernanda, también conocida como el profesor Luis Felipe Díaz, se diferencia de los tres casos anteriores tanto en el contenido de su narrativa como en el medio en el que se transmite, ya que es a través de dos largas entradas publicadas electrónicamente en la bitácora o blog (Post)modernidad puertorriqueña: «Datos de Luis Felipe y Lizza Fernanda. De 1976 a 2012», del 14 de abril de 2012 y «Memorias. Puertorriqueñidad y transculturación mariconil, de Luis Felipe Díaz/Lizza Fernanda», del 7 de mayo de 2012. Ambas han sido revisadas desde su publicación inicial e incluyen actualizaciones marcadas por fecha dentro del mismo texto, lo cual le da un elemento de palimpsesto o documento vivo sujeto a revisiones, expansiones y cambios. Resalta inmediatamente la particularidad de estos relatos, ya que el autor / la autora describe en minucioso detalle su nacimiento en 1950 y sus vivencias desde niño en los campos de Aguas Buenas (hije de padres puertorriqueños); su juventud en Estados Unidos (en Chicago, en el barrio de Lincoln Park) a partir de 1965 y luego el regreso a Puerto Rico y la vida de hombre gay que practicó el arte del transformismo por décadas a partir de 1976 (cuando tenía veintiséis ańos); nuevos desplazamientos, primero a Chicago y luego Nueva York; y finalmente la asunción de una identidad más cercana (pero no equivalente) a lo que ahora identificamos como «trans».

La historia de vida que se presenta en «Datos de Luis Felipe y Lizza Fernanda. De 1976 a 2012» y en «Memorias. Puertorriqueñidad y transculturación mariconil» no corresponde a la trama o marco narrativo más tradicional que enfatiza conflictos de infancia o de juventud para llegar a afirmar una verdadera identidad transgénero. Al contrario: Luis Felipe / Lizza Fernanda traza un mapa de grandes satisfacciones y retos en múltiples lugares y en distintos momentos. Esto incluye Chicago, adonde su familia se mudó durante su adolescencia, y Río Piedras (parte de San Juan), localidad a la que regresó para cursar estudios universitarios de subgrado en la Universidad de Puerto Rico. Las exploraciones vitales continúan y se expanden en Chicago, adonde fue para obtener su maestría, momento resal-

13 Antonio Santini, comunicación vía Facebook Messenger, 28 de septiembre de 2020. 
tado en los textos como época de su entrada en el mundo gay y del transformismo. Más tarde fue a Minnesota para cursar estudios doctorales. Su periplo culmina con el regreso al Caribe para convertirse en profesor usando el nombre de Luis Felipe Díaz, primero en la Universidad Interamericana y luego en el recinto de Río Piedras de la Universidad de Puerto Rico. Allí trabajó como catedrático en el Departamento de Estudios Hispánicos dictando cursos sobre literatura espańola, latinoamericana y caribeña y publicando numerosos estudios académicos. En este sentido, las memorias de Luis/Lizza son tanto memorias "gais" como memorias «trans»: reconocen la dualidad de la experiencia vital y no buscan negar una en pro de la otra. Las dos se integran como extensiones dinámicas y como reflejo de una rica vida múltiple que rompe esquemas y confunde por su falta de adhesión a parámetros más conocidos.

La cuidadosa negociación de esta compleja identidad (profesor universitario de día; artista del transformismo de noche, o durante vacaciones o en su tiempo libre; a veces hombre gay de apariencia muy masculina pero también transformista que deviene mujer trans) se narra acompañada por una cuidadosa descripción de su entorno social, algo que también vemos (tal vez de manera distinta) en los relatos de Rivera, Woodlawn y Soraya. Aquí percibimos cómo estas narrativas autobiográficas sirven no sólo como retratos individuales, sino también como recuentos históricos, sociales y culturales que trazan mapas urbanos de espacios en ocasiones marginales (el mundo social de personas LGBTQ latinas en San Juan, Chicago y Nueva York).

Tanto los relatos de Woodlawn y de Soraya como el de Lizza Fernanda / Luis Felipe indican su paso entre Puerto Rico y Estados Unidos (un cruce de fronteras), que en el caso de Soraya y especialmente en el de Lizza Fernanda tiene más marcados dejos de migración circular (la experiencia de pasar períodos importantes en más de un lugar, manteniendo lazos en múltiples sitios). Esta migración constituye un fenómeno que caracteriza la experiencia puertorriqueńa contemporánea, una migración identificada como «transnacional» y muy particular, ya que se trata de «una nación sin estado" (Duany 119); es una migración colonial entre el territorio subyugado y la metrópoli. De hecho, podemos decir que es precisamente este paso entre dos (o más) lugares el que permite y fomenta la circulación de ideas e identidades, que se nutren ya sea del anonimato de una gran ciudad (Chicago, Nueva York) o de las múltiples oportunidades disponibles (por ejemplo, de numerosos espacios artísticos). Como indica Díaz, este ir y venir fue una "gran experiencia bilingüe y bicultural que me haría muy distinto e híbrido culturalmente [...]. Era un jíbaro de Aguas Buenas que se había modernizado de una manera muy peculiar (aburguesada, creo) en Chicago con una diversidad muy amplia de gente, ya locas o heterosexuales» (Díaz Datos).

La historia de vida de Lizza Fernanda se esboza reconociendo dos identidades marcadas por dos nombres (Luis Felipe y Lizza Fernanda), que se relacionan de maneras interesantes y se van fusionando, pero que también mantienen rasgos independientes. Díaz describe esta doble percepción al indicar que «Se corrió la voz entre ellos de que yo tenía algo así como una doble personalidad: podía ser muy masculino cuando vestía comúnmente de varón, y mientras estaba trasvestido 
parecía una artista del cine mejicano» (Datos). Y la persona (la identidad) artística se exterioriza, al menos inicialmente (en los ańos setenta), pues responde a deseos sociales, ya que, como indica, «en mi caso, el vestirse de mujer no era nada privado sino público, para espectáculos, contrariamente a muchos otros que lo hacían por cuestiones secretísimas y sexuales» (Datos).

Si bien Luis Felipe Díaz nació en Aguas Buenas en 1950 y se crio entre Puerto Rico y Estados Unidos, Lizza Fernanda es una talentosa artista del transformismo que surgió en Chicago en 1976 para presentarse inicialmente en fiestas entre amigos y luego en diversos escenarios profesionales del mundo de ambiente gay latino, que frecuentemente contaban con comensales de clase trabajadora e inmigrante. Como indican sus crónicas y sus videos en YouTube, Lizza Fernanda se especializa en el arte del doblaje o fonomímica de canciones románticas y picantes de estrellas latinoamericanas, caribeñas, españolas, estadounidenses y galesas tales como María Martha Serra Lima (de quien interpreta el bolero Encadenados), Shirley Bassey (Diamonds Are Forever), Rocío Dúrcal (Porque te quiero), Liza Minnelli (New York, New York) y Eartha Kitt (Where Is My Man), al igual que de Olga Guillot y Blanca Rosa Gil; también interpreta temas en francés (por ejemplo, a Eartha Kitt cantando Je cherche un homme). Su estilo es mayormente serio, ya que busca captar la elegancia y belleza de estas artistas blancas, afroamericanas, afroeuropeas y latinas. Por consiguiente, sus representaciones no son burdas parodias ni tienen elementos de humor gratuito, aunque sí mantienen cierto salero; se caracterizan por profesionalismo, gran empeño y una cuidadosa atención a los vestuarios y al movimiento corporal. La meta es presentar una imagen idealizada, a la vez que se mantiene un agradable y respetuoso discurso con el público espectador.

Si bien Lizza Fernanda comenzó su carrera artística como travesti, transformista o drag queen, según ha ido transformando su cuerpo y su identidad se entiende mejor como una artista "trans», aunque se resiste a estas etiquetas y refuta una categorización simplista, abogando por la complejidad y multiplicidad:

Como Lizza suelo ser tranquilamente fugaz en estos menesteres del ser corporal. Lizza es felizmente parte del ente-ser que representa Luis Felipe (que es híbrido en su identidad genérica) y ha ido creciendo, como parte integral de un Uno transidentitario y nomádico en cuestiones de personalidad, capaz de viajar a espacios prohibidos y nunca mencionados por la sociedad conservadora y tradicional (Datos).

Esta hibridez que caracteriza el «Uno transidentitario y nomádico» de Luis Felipe / Lizza Fernanda implica una apertura a modelos más amplios y menos rígidos de la identidad que resuenan con los pronunciamientos más recientes de la dominicana Johan Mijail, quien también se resiste a definiciones y categorías limitantes en un contexto caribeño.

En su historia de vida, Díaz también nos habla sobre sus intereses intelectuales, su trayectoria académica, sus lecturas teóricas y sus ideas sobre el género y la sexualidad, pues Lizza Fernanda / Luis Felipe transita de manera complicada, contradictoria y liberadora a través de las categorías de homosexual, loca, travesti, transformista, transgénero, intelectual, artista, profesor, catedrático y ser humano. Como indica, 
Yo era así... híbrido; masculino y femenino a la vez, un mariconazo no sólo en la cuestión sexual sino también en la de cambios de aspectos genéricos [...]. El que vistiera de mujer mayormente no tenía nada con ser feliz o infeliz, ni con represión o miedo; tenía que ver con mi acometimiento y natural seguimiento interno de mi ser como transgénero y ser humano de un existenciario en libre-en-proceso y devenir; y la gente no sabe ni entiende casi nada de eso (Datos).

Es por consiguiente crucial resaltar esta postura muy particular, que ve en el devenir mujer algo refrescante y lleno de sentido, no acompañado de una angustia existencial reprimida, sino que tiene mucho que ver con la especificidad de la edad y del proceso de envejecimiento:

Nunca tuve problemas en mi vestir de varón, como lo hice desde niño; sólo que de mujer ahora, en esta etapa de mi alta vida, todo parece más interesante, entretenido y complejo desde mi mirada trans. Es una continuidad de mi proceso de vida. También he visto que mi envejecimiento como varón no es el más idóneo... ¡y de mujer me veo mejor! [...] Ahora que siempre visto de mujer sigo siendo un Luis Felipe transformado. ¡Porque me da la real gana! Soy la Sra. Luis Felipe Díaz o el Sr. Lizza Fernanda (Díaz Datos).

Esta doble afirmación potencia espacios de libertad y concuerda con los planteos de Néstor Perlongher en «Los devenires minoritarios»: «Devenir no es transformarse en otro, sino entrar en alianza (aberrante), en contagio, en inmistión con el (lo) diferente. El devenir no ya de un punto a otro, sino que entra en el "entre" del medio, es ese "entre"" (130-131, cursiva en el original).

En sus valiosas crónicas autobiográficas, Díaz nos cuenta sobre sus presentaciones artísticas en Chicago (donde compartió escenario con estrellas de la talla de Miss Ketty Teanga, artista ecuatoriana criada en Puerto Rico y documentada por Ramón Rivera-Servera $)^{14}$, en Nueva York, donde se ha presentado con Mirkala Crystal; y de una gama de escenarios en Puerto Rico, donde muchísimas personas la conocen y ha aparecido tanto en los principales periódicos (por ejemplo, el artículo "Travestido en pos de su ser», de Lilliam Irizarry, publicado en El Nuevo Día en 2012) como en la televisión, incluyendo en el programa Día a Día de Telemundo Puerto Rico, con Raymond Arrieta ("Día a Día, Sobre la Mesa: Profesor universitario da clases vestido de mujer») y en Ahora Podemos Hablar con Carmen Jovet, transmitido por WIPR Puerto Rico TV. También ha aparecido en los medios latinoamericanos, por ejemplo, en el programa peruano 24 Horas de Panamericana Televisión filmado durante su visita a ese país en 2013 para participar en la Feria Internacional del Libro, al igual que en el programa dominicano Nuria Investigación Periodistica en 2014, con la periodista Nuria Piera. (Muchas de estas entrevistas y reportajes se encuentran disponibles en YouTube).

14 También ver La Fountain-Stokes, Torres y Rivera-Servera, en donde se esboza un mapa más amplio de la vida queer latina de Chicago, incluyendo las representaciones artísticas de Miss Ketty Teanga. 
Como se aprecia en esta discusión, resulta crucial reconocer la multidimensionalidad de la experiencia vital de Luis Felipe / Lizza Fernanda. En tanto académico, el profesor Luis Felipe Díaz ha publicado numerosos libros, incluyendo Ironia e ideología en La Regenta de Leopoldo Alas (1992), Modernidad literaria puertorriqueña (2005), La na(rra)ción en la literatura puertorriqueña (2008), De charcas, espejos, infantes y velorios en la literatura puertorriqueña (2010), Modernidad, postmodernidad y tecnocultura actual (2011) y Eros y violencia en la novela hispanoamericana del siglo XX (2015). Esta obra académica ha aspirado a modernizar los estudios de la literatura puertorriqueña, latinoamericana e hispánica con aportes de la teoría crítica contemporánea, estableciendo importantes diálogos con otrxs académicxs tales como Juan G. Gelpí, Rubén Ríos Ávila, Malena Rodríguez Castro, Juan Otero Garabís y Melanie Pérez Ortiz, colegas docentes en la Universidad de Puerto Rico.

El cine documental y los foros académicos queer también han servido para ampliar el alcance de la obra y pensamiento crítico y artístico de Luis Felipe Díaz. En 2015 se estrenó el cortometraje Luis/Lizza, realizado por el director puertorriqueño Joelle González-Laguer, que presenta entrevistas con Lizza Fernanda y con sus estudiantes en la Universidad de Puerto Rico (incluyendo a una estudiante fundamentalista cristiana que adora a su profesor) y escenas de las representaciones artísticas de Lizza Fernanda; esta película es un interesante contrapunto con Mala Mala, un filme más largo que se enfoca en nueve personas. Las concurridas presentaciones de Luis/Lizza han servido como foro para números musicales y valiosos conversatorios, por ejemplo, en el Primer Coloquio de Literatura Queer en la Universidad de Puerto Rico, Recinto de Carolina, en 2015 y en el Sexto Coloquio «iDel Otro La’o?: perspectivas sobre sexualidades queer», que se llevó a cabo en el Recinto de Mayagüez de la UPR en 2016. En ambas ocasiones, Lizza Fernanda sedujo al público espectador, contando infinidad de detalles sobre su vida, el arte y la literatura hispana y universal. También ha deleitado a su público en sus presentaciones artísticas en lugares de ambiente en Puerto Rico tales como Tía Marías Liquor Store y Zal Zi Puedes, ambas en Santurce y en la Librería Mágica de Río Piedras.

\section{CONCLUSIONES}

Los relatos autobiográficos y las memorias queer puertorriqueñas documentan vivencias únicas y profundas luchas sociales, que han acompañado significativos cambios históricos. La falta de más publicaciones tradicionales (en forma de libros) y los retos experimentados por algunas personas trans nos impulsan a apreciar y rescatar una variedad de textualidades, gesto parecido al que Rafael M. Mérida Jiménez propone en su artículo «Hacia una cartografía de las textualidades autobiográficas trans en España». La lectura cuidadosa de los discursos y de las entrevistas en inglés de Sylvia Rivera, de A Low Life in High Heels, de Holly Woodlawn; de Hecha a mano. Disforia de género, de Soraya, y de las memorias de Luis Felipe Díaz / Lizza Fernanda publicadas en el blog (Post)modernidad puertorriqueña nos ofrecen una visión sumamente variada -e incluso contradictoria- de vidas profundamente diferentes, marcadas por la homofobia, la transfobia y por las complejida- 
des de la puertorriqueñidad móvil transatlántica y transcaribeña en el contexto del capitalismo, el colonialismo y el racismo estadounidense.

La motivación central de este artículo radicó en documentar y analizar la experiencia trans, con la esperanza de que pronto haya académicxs o investigadorxs trans puertorriqueńxs que se dediquen a este empeño y que complementen, reten o transformen la visión que he ofrecido. Como motivación adicional se encuentra el deseo de poner este corpus en conversación con la teoría queer (o cuir) y trans de color generada en las Américas y en España y de visualizar un puente de conocimiento y diálogo.

Ya sea en inglés, en español o en ambas lenguas, las figuras centrales resaltadas en este artículo, cuatro «boricuas cruzando fronteras», transforman nuestras concepciones de la puertorriqueñidad, de la experiencia trans y del género autobiográfico, pero también de lo que significa ser latina en Estados Unidos, ser afrodescendiente o comprometida con la lucha antirracista, ser activista o profesora universitaria o artista de cabaret o persona que vive en la calle y trabaja en la prostitución y que busca ofrecerles albergue a niñes y jóvenes sin casa. Este es un gesto que reaparece en la escritura más reciente de la autora y activista argentina Marlene Wayar, con su énfasis en la infancia como «un espacio potente para construcción de una Nostredad, en el que no estamos permanentemente en guardia y con miedo a perder lo que tenemos o a ser víctimas de un ataque» (Wayar 18-19).

La inclusión de la categoría del testimonio y de entrevistas, discursos y entradas de blogs en Internet complementa y expande los relatos publicados en libros, proponiendo que hay algo particular y diferente en la experiencia puertorriqueña, caribeña, latinoamericana y latina que se aprecia al reconocer las interconexiones, es decir, al aproximarnos a los textos desde la perspectiva de la interseccionalidad. Los textos de Luis Felipe / Lizza Fernanda también nos ayudan a complejizar las fronteras entre las memorias "gais» y las memorias «trans», posicionándose precisamente en un espacio liminal parecido a la frontera porosa y provocadora teorizada por Gloria Anzaldúa en su valioso tratado Borderlands/La frontera: La nueva mestiza (1987). En este contexto, el cruce del mar Caribe o del océano Atlántico o del río Hudson o del lago Míchigan se vuelve válvula que ofrece multiplicidad de significantes y experiencias. También se convierte en un espacio textual político de translocas, travestis, mujeres con disforia de género y personas trans, de «boricuas cruzando fronteras» de múltiples maneras a finales del siglo veinte y en los albores del siglo veintiuno. 


\section{REFERENCIAS BIBLIOGRÁFICAS}

Acevedo, David Caleb. Diario de una puta humilde. San Juan: Erizo Editorial, 2012.

Acevedo, David Caleb, Agosto Rosario, Moisés y Negrón, Luis (eds.). Los otros cuerpos. Antología de temática gay, lésbica y queer desde Puerto Rico y su diáspora. San Juan: Editorial Tiempo Nuevo, 2007.

Agencia EFE. «Anuncian primer Centro de Ayuda para el Adulto LGBTT en San Juan de P. Rico». 14 de mayo de 2019. <https://bit.ly/3xDdk2v>.

Alexander, M. Jacqui. Pedagogies of Crossing: Meditations on Feminism, Sexual Politics, Memory, and the Sacred. Durham, NC: Duke University Press, 2005.

Álvarez Rivera, Manuel. «Elección de Legisladores Municipales». Elecciones en Puerto Rico. 18 de noviembre de 2020. <https://bit.ly/3nxReto>.

Anzaldúa, Gloria. Borderlands/La frontera: La nueva mestiza. Trad. Carmen Valle. Madrid: Capitán Swing, 2016 (1987).

Aponte Parés, Luis, Arroyo, Jossianna, Crespo-Kebler, Elizabeth, La Fountain-Stokes, Lawrence y Negrón-Muntaner, Frances (eds.). «Puerto Rican Queer Sexualities». Número temático. Centro: Journal of the Center for Puerto Rican Studies, vol. 19, núm. 1 (2007).

Ayala, César J. y Bernabe, Rafael. Puerto Rico en el siglo americano. Su historia desde 1898. San Juan: Ediciones Callejón, 2011.

BARradas, Efraín. «Etnografía del hostigamiento: Sobre las memorias de Joseph F. Delgado». 80 grados, 11 de diciembre de 2017. <https://bit.ly/3gOJjGK>.

Bornstein, Kate. A Queer and Pleasant Danger: A Memoir. Boston: Beacon Press, 2012.

Castro PÉrez, Joel I. «La lucha por el derecho a ser. Una historia de transfobia institucional, 19952018». CENTRO: Journal of the Center for Puerto Rican Studies, vol. 30, núm. 2 (2018), pp. 478-501.

Cruz Bernal, Mairym. Entrevista telefónica, 5 de noviembre de 2020.

Cruz-Malavé, Arnaldo. Queer Latino Testimonio, Keith Haring, and Juanito Xtravaganza: Hard Tails. New York: Palgrave Macmillan, 2007.

Cruz-Malavé, Arnaldo. «Testimonio», en Vargas, Deborah R., Mirabal, Nancy Raquel y La Fountain-Stokes, Lawrence (eds.), Keywords for Latinalo Studies, New York: New York University Press, 2017, pp. 228-232.

Delgado, Joseph F. Ser diferente en Puerto Rico. El peso de la memoria. Bogotá: Ediciones El Laberinto, 2017.

Delgado Rivera, José Orlando. «Fallece Soraya Santiago, ícono de la comunidad LGBTTQ y defensora de la igualdad». El Nuevo Día, 22 de septiembre de 2020. <https://bit.ly/3gQBuRa>.

Díaz, Luis Felipe. Ironía e ideología en La Regenta de Leopoldo Alas. New York: Peter Lang, 1992.

DíAz, Luis Felipe. Modernidad literaria puertorriqueña. San Juan: Editorial Isla Negra y Editorial Cultural, 2005.

DíAz, Luis Felipe. La na(rra)ción en la literatura puertorriqueña. San Juan: Ediciones Huracán, 2008.

DíAz, Luis Felipe. De charcas, espejos, infantes y velorios en la literatura puertorriqueña. San Juan: Editorial Isla Negra, 2010.

DíAz, Luis Felipe. Modernidad, postmodernidad y tecnocultura actual. Río Piedras: Publicaciones Gaviota, 2011. 
DíAz, Luis Felipe. «Datos de Luis Felipe y Lizza Fernanda. De 1976 a 2012». (Post)modernidad puertorriqueña, 14 de abril de 2012. <https://bit.ly/3gRtaAC>.

DíAz, Luis Felipe. «Memorias. Puertorriqueñidad y transculturación mariconil, de Luis Felipe Díaz/Lizza Fernanda». (Post)modernidad puertorriqueña, 7 de mayo de 2012. < https://bit. ly/3e4LZ18>.

Díaz, Luis Felipe. «Luis Felipe Díaz-Entrevista Carmen Jovet». YouTube, 3 de noviembre de 2012. $<$ https://bit.ly/3xuIskF>.

DíAz, Luis Felipe. Eros y violencia en la novela hispanoamericana del siglo XX. San Juan: Isla Negra Editores, 2015.

Díaz-Morales, Julián. «Transexualidad. Tabú Juridico». Revista Jurídica de la Universidad de Puerto Rico, 81:1 (2012), pp. 171-194.

DuAny, Jorge. «Nación, migración, identidad: sobre el transnacionalismo. A propósito de Puerto Rico", en Obra selecta, Valencia: Aduana Vieja Editorial, 2021, pp. 119-139.

Duberman, Martin. Stonewall. New York: Plume, 1994.

Ellis, Robert Richmond. The Hispanic Homograph: Gay Self-Representation in Contemporary Spanish Autobiography. Urbana: University of Illinois Press, 1997.

Ellis, Robert Richmond. They Dream Not of Angels But of Men: Homoeroticism, Gender, and Race in Latin American Autobiography. Gainesville: University Press of Florida, 2002.

Falconí Trávez, Diego (ed.). Inflexión marica. Escrituras del descalabro gay en América Latina. Barcelona: Editorial Egales, 2018.

Falconí Trávez, Diego, Castellanos, Santiago y Viteri, María Amelia (eds.). Resentir lo queer en América Latina: Diálogos desdelcon el Sur. Barcelona: Editorial Egales, 2014.

Feinberg, Leslie. Transgender Warriors: Making History from Joan of Arc to Dennis Rodman. Boston: Beacon Press, 1996.

Feinberg, Leslie. Trans Liberation: Beyond Pink or Blue. Boston: Beacon Press, 1998.

Galarte, Francisco J. Brown Trans Figurations: Rethinking Race, Gender, and Sexuality in Chicanx/ Latinx Studies. Austin: University of Texas Press, 2021.

Gan, Jessi. «"Still at the Back of the Bus”: Sylvia Rivera’s Struggle». CENTRO: Journal of the Center for Puerto Rican Studies, 19:1 (2007), pp. 124-139.

García Ramis, Magali. Felices días, Tío Sergio. San Juan: Editorial Cultural, 1986.

Garriga-López, Claudia Sofía, Lopes, Denilson, Rizki, Cole y Rodríguez, Juana María (eds.). «Trans Studies en las Américas». Número temático. TSQ: Transgender Studies Quarterly, 6:2 (2019).

Gómez, Julio (dir.). Portrait of a Lady: Story of Barbra Herr. Filme. 2012. <https://bit.ly/3eETlb2>.

GonzÁLez-Laguer, Joelle (dir.). Luis/Lizza. Filme. 2014. <https://bit.ly/3vu7n5P>.

Guzmán, Manolo. Gay Hegemony/Latino Homosexualities. New York: Routledge, 2006.

Hames-García, Michael. «Queer Theory Revisited», en Hames-García, Michael y Martínez, Ernesto Javier (eds.), Gay Latino Studies: A Critical Reader, Durham, NC: Duke University Press, 2011, pp. 19-45.

Herr, Barbra. «Trans-Mission», en Vásquez, Eva Cristina (ed.), Círculo de plata. Antología de estrenos mundiales de Teatro Círculo, Nueva York: Artepoética Press, 2021, pp. 325-346.

IrizArry, Lilliam. «Travestido en pos de su ser». El Nuevo Día, 2 de noviembre de 2012. <https:// bit.ly/2PBh1EF>. 
JACQUES, Juliet. «Forms of Resistance: Uses of Memoir, Theory, and Fiction in Trans Life Writing». Life Writing, 14:3 (2017), pp. 357-370. DOI: https://doi.org/10.1080/14484528.2017.1328301.

La Fountain-Stokes, Lawrence. Queer Ricans: Cultures and Sexualities in the Diaspora. Minneapolis: University of Minnesota Press, 2009.

La Fountain-Stokes, Lawrence. "Gay Shame, Latina- and Latino-Style: A Critique of White Queer Performativity», en Hames-García, Michael y Martínez, Ernesto Javier (eds.), Gay Latino Studies: A Critical Reader, Durham, NC: Duke University Press, 2011, pp. 55-80.

La Fountain-Stokes, Lawrence. «Mala Mala y la representación transgénero y transformista en el cine puertorriqueño», en Cuesta, Mabel (ed.), Nuestro Caribe: Poder, raza y postnacionalismos desde los límites del mapa LGBTQ, San Juan: Editorial Isla Negra, 2016, pp. 185-200.

La Fountain-Stokes, Lawrence. Escenas transcaribeñas. Ensayos sobre teatro, performance y cultura. San Juan: Editorial Isla Negra, 2018.

La Fountain-Stokes, Lawrence. «The Life and Times of Trans Activist Sylvia Rivera», en Ramos-Zayas, Ana Y. y Rúa, Mérida M. (eds.), Critical Dialogues in Latinx Studies, New York: New York University Press, 2021, pp. 241-253.

La Fountain-Stokes, Lawrence. Translocas: The Politics of Puerto Rican Drag and Trans Performance. Ann Arbor: University of Michigan Press, 2021.

La Fountain-Stokes, Lawrence y Martínez-San Miguel, Yolanda (eds.). «Revisiting Queer Puerto Rican Sexualities». Número temático. CENTRO: Journal of the Center for Puerto Rican Studies, vol. 30, núm. 2 (2018).

La Fountain-Stokes, Lawrence, Torres, Lourdes y Rivera-Servera, Ramón H. «Towards an Archive of Latina/o Queer Chicago: Art, Politics, and Social Performance», en Austin, Jill y Brier, Jennifer (eds.), Out in Chicago: LGBT History at the Crossroads, Chicago: Chicago History Museum, 2011, pp. 127-153.

Laureano, Javier E. San Juan Gay. Conquista de un espacio urbano de 1948 a 1991. San Juan: Editorial del Instituto de Cultura Puertorriqueña, 2016.

López Torregrosa, Luisita. The Noise of Infinite Longing: A Memoir of a Family and an Island. New York: Rayo/HarperCollins Publishers, 2004.

López Torregrosa, Luisita. Before the Rain: A Memoir of Love and Revolution. Boston: Houghton Mifflin Harcourt, 2012.

LoveTapesCollective. «L020A Sylvia Rivera, «Y’all Better Quiet Down» Original Authorized Video, 1973 Gay Pride Rally NYC». YouTube, 23 de mayo de 2019. <https://bit. ly/3nwuZnO>.

Lozada, Ángel. La patografía. Novela. México: Editorial Planeta Mexicana, 1998.

LozAda, Ángel. No quiero quedarme sola y vacía. San Juan: Editorial Isla Negra, 2006.

Martorell, Antonio. La piel de la memoria. Cayey: Ediciones Envergadura, 1991.

MÉRIDA JimÉnez, Rafael M. «Hacia una cartografía de las textualidades autobiográficas trans en España», en Ingenschay, Dieter (ed.), Eventos del deseo. Sexualidades minoritarias en las culturas-literaturas de España y Latinoamérica a fines del siglo XX, Madrid: Iberoamericana Vervuert, 2018, pp. 155-168.

MijaIL, Johan. «travesTismo cultUral: tecnodEcolonialidad, promiscuidad escRitural dominicanCUIR». Hostos Review/Revista Hostosiana, 16 (2020), pp. 59-63. <https://bit.ly/2R6aZfz>.

Molloy, Sylvia. Acto de presencia. La escritura autobiográfica en Hispanoamérica. México: Fondo de Cultura Económica, 1996. 
Muñoz, José Esteban. Disidentifications: Queers of Color and the Performance of Politics. Minneapolis: University of Minnesota Press, 1999.

Muñoz, José Esteban. The Sense of Brown. Durham, NC: Duke University Press, 2020.

Negrón-Muntaner, Frances. Boricua Pop: Puerto Ricans and the Latinization of American Culture. New York: New York University Press, 2004.

Negrón-Muntaner, Frances (ed.). None of the Above: Puerto Ricans in the Global Era. New York: Palgrave Macmillan, 2007.

Ortiz, Reyna. T: Stands for Truth. Chicago: Transfusion, 2017.

Pantoja, Antonia. Memoir of a Visionary: Antonia Pantoja. Houston: Arte Público Press, 2002.

Perales, Rosalina. «El travestismo como arte: entrevista comentada a Luis Felipe Díaz-Lizza Fernanda». Argus-a, 6:25 (septiembre 2017). <http://www.argus-a.com.ar/archivos-dinamicas/1267-1.pdf>.

Peralta, Jorge Luis y Mérida Jiménez, Rafael M. (eds.). Memorias, identidades y experiencias trans. (In) visibilidades entre Argentina y España. Buenos Aires: Editorial Biblos, 2015.

Perlongher, Néstor. Los devenires minoritarios. Barcelona: Editorial Diaclasa, 2016.

Piera, Nuria. «Catedrático en la Universidad de Puerto Rico, pasa de Luis Felipe a Lizza Fernanda». YouTube, 8 de diciembre de 2014. <https://bit.ly/3gPLKsT>.

Platero Méndez, R. Lucas. «Metáforas y articulaciones para una pedagogía crítica sobre la interseccionalidad». Quaderns de Psicologia, 16:1 (2014), pp. 55-72. <https://bit.ly/3xD0dhy>.

Primera hora. «Pareja trans celebra el nacimiento de su bebé en Puerto Rico». 20 de julio de 2020. $<$ https://bit.ly/3eIhYn1>.

Primera hora. «Pareja trans obtiene certificado de nacimiento de su bebé». 4 de agosto de 2020. <https://bit.ly/3gP0PL6>.

Prosser, Jay. «Mirror Images: Transsexuality and Autobiography». Second Skins: The Body Narratives of Transsexuality. New York: Columbia University Press, 1998, pp. 99-134.

Ramos Otero, Manuel. No tener miedo a las palabras. San Juan: Folium, 2020.

Retzloff, Tim. «Eliding Trans Latino/a Queer Experience in U.S. LGBT History: José Sarria and Sylvia Rivera Reexamined». CENTRO: Journal of the Center for Puerto Rican Studies, 19:1 (2007), pp. 140-161.

Ríos Ávila, Rubén. «Pornoliteratura». 80grados, 17 de enero de 2014. <https://bit.ly/2QGpnew>.

Rivera, Sylvia. «I'm Glad I Was in the Stonewall Riot», en Feinberg, Leslie, Trans Liberation: Beyond Pink or Blue, Boston: Beacon Press, 1998, pp. 106-109.

Rivera, Sylvia. "Queens in Exile, The Forgotten Ones», en Nestle, Joan, Howell, Clare y Wilchins, Riki (eds.), GenderQueer: Voices from Beyond the Sexual Binary, Los Angeles: Alyson Publications, 2002, pp. 67-85.

Rivera, Sylvia. «Sylvia Rivera's Talk at LGMNY, June 2001, Lesbian and Gay Community Services Center, New York City». CENTRO: Journal of the Center for Puerto Rican Studies, 19:1 (2007), pp. 116-123.

Rivera, Sylvia. «Transvestites: Your Half Sisters and Half Brothers of the Revolution». Come Out, 2:8 (1972), pp. 10.

Rivera-Servera, Ramón H. «History in Drag: Latina/o Queer Affective Circuits in Chicago», en Valerio-Jiménez, Omar, Vaquera-Vásquez, Santiago y Fox, Claire F. (eds.), The Latinalo Midwest Reader, Champaign: University of Illinois Press, 2017, pp. 185-196. 
Robles, Frances. «Soraya Santiago Solla, Transgender Trailblazer, Dies at 72». New York Times, 2 de octubre de 2020. <https://nyti.ms/3e2WeTGl>.

Rodríguez Madera, Sheilla. Género trans. Transitando por las zonas grises. San Juan: Terranova Editores, 2009.

Román Samot, Wilkins. «Ser diferente en Puerto Rico. El peso de la memoria, de Joseph F. Delgado». Rebelión, 15 de junio de 2019. <https://bit.ly/3t77NNU>.

Rondot, Sarah Ray. “"Bear Witness” and "Build Legacies”: Twentieth- and Twenty-First-Century Trans* Autobiography». alb: Auto/Biography Studies, 31:3 (2016), pp. 527-551.

Salas Rivera, Raquel. xlex/exis. poemas para la nación. Tempe: Bilingual Press, 2020.

Santana, Dora Silva. «Transitionings and Returnings: Experiments with the Poetics of Transatlantic Water». TSQ: Transgender Studies Quarterly, 4:2 (May 2017), pp. 181-190. DOI: https:// doi.org/10.1215/23289252-3814973.

Schewe, Elizabeth. «Serious Play: Drag, Transgender, and the Relationship between Performance and Identity in the Life Writing of RuPaul and Kate Bornstein». Biography, 32:4 (2009), pp. 670-695.

Smith, Sidonie y Watson, Julia. Reading Autobiography: A Guide for Interpreting Life Narratives. Segunda ed. Minneapolis: University of Minnesota Press, 2010.

Snorton, C. Riley. Black on Both Sides: A Racial History of Trans Identity. Minneapolis: University of Minnesota Press, 2017.

Soraya (Bárbara Santiago Solla). Hecha a mano. Disforia de género. San Juan: Lúdika Proyecto, 2014.

StREET TRANSVESTITE ACtION ReVOLUTIONARIES. Supervivencia, revuelta y lucha queer antagonista. Madrid: Distribuidora Peligrosidad Social, 2014. <https://bit.ly/3vwsR20>.

StreEt TRAnsvestite Action ReVolutionaries. Survival, Revolt, and Queer Antagonist Struggle. N.p.: Untorelli Press, 2013. <https://bit.ly/3ua57Rg>.

Stryker, Susan y Aizura, Aren Z. (eds.). The Transgender Studies Reader 2. New York: Routledge, 2013.

Tedjasukmana, Chris. «Y'all Better Quiet Down». Videoactivism, 12 de agosto de 2016. <https:// bit.ly/3nAeJC3>.

Telemundo Puerto Rico. «Día a Día, Sobre la Mesa: Profesor universitario da clases vestido de mujer». 21 de febrero de 2015. <https://bit.ly/3e47WgY>.

Torres, Lourdes. "Queering Puerto Rican Women's Narratives: Gaps and Silences in the Memoirs of Antonia Pantoja and Luisita López Torregrosa». Meridians, 9:1 (2009), pp. 83-112.

Torres Rivera, Gerardo. Memorias de un Setentón. <https://bit.ly/3t5hhtd>.

Torres Rivera, Gerardo. Radiotransistor. Carolina: Terranova Editores, 2011.

VAlCÁrCel, Xavier. Aterrizar no es regreso. Carolina: Alayubia, 2019.

WaYAr, Marlene. Travesti. Una teoría lo suficientemente buena. Buenos Aires: Editorial Muchas Nueces, 2018.

Woodlawn, Holly y Copeland, Jeffrey. A Low Life in High Heels: The Holly Woodlawn Story. New York: Perennial, 1992. 